\title{
Paralisia Periódica Hipocalêmica na Síndrome de Sjögren
}

\section{Hypokalemic Periodic Paralysis in Sjögren's Syndrome}

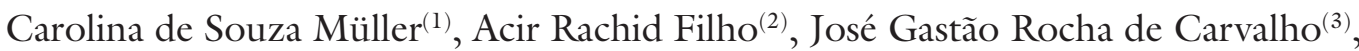 \\ Sinara da Silva Freitas ${ }^{(1)}$, Carlos Frederico Rodrigues Parchen ${ }^{(4)}$
}

\section{RESUMO}

Na síndrome de Sjögren, o acometimento subclínico dos túbulos renais pode afetar uma parcela significativa de pacientes. A maioria apresenta acidose tubular renal distal (tipo 1), que pode se constituir na primeira manifestação da doença auto-imune e contribuir para sua maior duração e gravidade. A depleção de potássio, resultante da acidose tubular renal distal, pode ser extremamente grave e colocar em risco a vida do paciente se não diagnosticada e tratada. A paralisia periódica hipocalêmica foi observada em quase $40 \%$ dos pacientes com síndrome de Sjögren e acidose tubular renal distal. Descrevemos, a seguir, o caso de uma paciente com diagnóstico de síndrome de Sjögren, estabelecido há quatro anos, que apresentou amortecimento e fraqueza em membros inferiores com dificuldade respiratória. Houve agravamento dos sintomas e necessidade de internamento em Unidade de Terapia Intensiva. À admissão, verificou-se potássio sérico de $2 \mathrm{mEq} / \mathrm{L}$. Com o diagnóstico de paralisia hipocalêmica, procedeu-se ao tratamento imediato com reposição parenteral de $\mathrm{KCl}$ 19,1\% e oxigênio suplementar (máscara). Não houve necessidade de ventilação mecânica. A paciente recebeu alta com potássio sérico corrigido para $3,4 \mathrm{mEq} / \mathrm{L}$.

Palavras-chave: hipopotassemia, síndrome de Sjögren, acidose tubular renal.

\begin{abstract}
Subclinical renal tubular dysfunction in Sjögren's syndrome can affect a significant number of patients, the majority presenting with distal renal tubular acidosis (type 1). Such findings may be the first symptom of the auto-immune disease, and can contribute for a prolonged disease duration and severity. Potassium depletion resulting from distal renal tubular acidosis can be extremely severe, and can jeopardise patient's life, if its diagnosis and treatment are delayed. Hypocalemic periodic paralysis was observed in almost $40 \%$ of patients who suffer from Sjögren's syndrome and distal renal tubular acidosis. The case that follows describes a patient who was diagnosed with Sjögren's syndrome four years ago. Three days before being admitted to hospital, the patient complained that her lower limbs were numb and weak, and that breathing was difficult. Symptoms intensified, the patient was broght to the Intensive Care Unit, where the serum potassium was $2 \mathrm{mEq} / \mathrm{L}$ at admittance. Hypocalemic paralysis was diagnosed, and the patient was immediately treated with IV KCl 19.1\% and supplementary oxygen by mask. Mechanical ventilation was not required. The patient was discharged with serum potassium corrected to $3.4 \mathrm{mEq} / \mathrm{L}$.
\end{abstract}

Keywords: hypokalemia, Sjögren's syndrome, renal tubular acidosis.

Serviço de Reumatologia e Nefrologia do Hospital de Clínicas da Universidade Federal do Paraná (UFPR). Recebido em 22/02/06. Aprovado, após revisão, em 06/05/06.

1. Residente de Reumatologia da UFPR

2. Professor Adjunto de Reumatologia da UFPR.

3. Professor Adjunto de Nefrologia da UFPR.

4. Especializando de Reumatologia da UFPR

Endereço para correspondência: Carolina de Souza Müller, Rua Geraldo Lipka, 65/1301, CEP 81200-590, Curitiba, PR, telefone: (41) 3373-3310, fax: (41) 3373-6894 / 3322-9098, e-mail: carolinamuller@brturbo.com.br 


\section{INTRODUÇÃO}

A síndrome de Sjögren, doença auto-imune inflamatória, afeta primariamente as glândulas exócrinas. Caracteriza-se, principalmente, por ceratoconjuntivite seca, xerostomia, xerotraquéia e ressecamento vaginal, que resultam do ressecamento das mucosas. Manifestações extraglandulares peri-epiteliais devem-se a infiltrados linfocíticos nos pulmões, rins e fígado e tendem a ocorrer mais precocemente na evolução da doença.

O envolvimento renal na síndrome de Sjögren exige atenção. Quando não corretamente identificada, a acidose tubular renal coloca em risco a vida do paciente. A própria condição de paralisia hipocalêmica resultante da acidose tubular renal pode constituir a primeira manifestação da doença auto-imune, diagnosticada até anos mais tarde.

Descrevemos a seguir uma paciente com diagnóstico de síndrome de Sjögren que durante a evolução apresentou necessidade de internamento em Unidade de Terapia Intensiva devido à paralisia hipocalêmica, decorrente de acidose tubular renal, até então não-identificada.

\section{RELATO DE CASO}

Paciente feminina, branca, de 31 anos, foi investigada quanto à possibilidade de síndrome de Sjögren há quatro anos, devido a queixa de boca e olhos secos. Demonstrou-se a presença de auto-anticorpos (FAN $>1: 640$ padrão pontilhado fino, anti-Ro/SS-A e anti-La/SS-B reagentes) e fator reumatóide (FR) em título elevado ( 820 $\mathrm{UI} / \mathrm{mL}$ ). Estava em acompanhamento há três anos, em uso de pilocarpina, solução oral de carmelose, colírio de hipromelose, corticosteróides em baixas doses, antiinflamatórios e metotrexato.

A paciente, nos três dias que precederam o internamento, passou a apresentar dor, amortecimento e fraqueza em membros inferiores, além de dificuldade respiratória. Nos dois dias subseqüentes, houve aumento da intensidade dos sintomas e extensão da fraqueza também para membros superiores.

Devido à gravidade do quadro clínico, procedeu-se ao internamento em Unidade de Terapia Intensiva. À admissão realizaram-se exames laboratoriais com os seguintes resultados: potássio $2,0 \mathrm{mEq} / \mathrm{L}$ (chegando a $1,6 \mathrm{mEq} / \mathrm{L}$ ), sódio $130 \mathrm{mEq} / \mathrm{L}$, creatinina $1,3 \mathrm{mg} / \mathrm{dL}, \mathrm{CPK} 136 \mathrm{U} / \mathrm{L}$ $(\mathrm{N}=27$ a $195 \mathrm{U} / \mathrm{L}), \mathrm{LDH} 324 \mathrm{U} / \mathrm{L}(\mathrm{N}=225$ a 450 $\mathrm{U} / \mathrm{L})$, cálcio $8,4 \mathrm{mg} / \mathrm{dL}(\mathrm{N}=8,5 \mathrm{a} 11 \mathrm{mg} / \mathrm{dL})$, fósforo $2,2 \mathrm{mg} / \mathrm{dL}(\mathrm{N}=2,5 \mathrm{a} 4,5 \mathrm{mg} / \mathrm{dL})$, glicemia $123 \mathrm{mg} / \mathrm{dL}$, hemograma, TSH e tiroxina (T4) normais. Com diagnóstico de paralisia hipocalêmica, foi tratada com reposição parenteral de KCL 19,1\% e oxigênio suplementar por máscara, sem necessidade de ventilação mecânica. Até o terceiro dia de internamento, a paciente mantinha-se com importante diminuição da força muscular em membros superiores e inferiores (grau III), com dor à mobilização durante exercícios de fisioterapia. Manteve-se reposição média diária de quatro ampolas de $10 \mathrm{~mL}$ de $\mathrm{KCl} 19,1 \%$ EV. Os níveis séricos de potássio eram dosados até duas vezes ao dia, apresentando elevação gradual. Após cinco dias de internamento, a paciente recebeu alta com potássio sérico corrigido para $3,4 \mathrm{mEq} / \mathrm{L}$.

\section{DISCUSSÃO}

O acometimento renal clinicamente evidente na síndrome de Sjögren pode ser constatado em até 5\% dos pacientes com a doença primária ${ }^{(1)}$. Apresenta-se na forma de nefrite intersticial ou glomerulonefrite. A primeira tende a manifestar-se mais cedo na evolução da doença, enquanto a glomerulonefrite constitui seqüela tardia. A doença glomerular constitui, de fato, apresentação pouco comum dentre os pacientes com síndrome de Sjögren, estando presente em torno de 2\% dos casos, nas suas formas membranosa ou membranoproliferativa, frequentemente associada ao achado de crioglobulinemia e hipocomplementenemia séricas.

O acometimento subclínico dos túbulos renais representa o mais prevalente e preocupante envolvimento do rim na síndrome de Sjögren. Pode estar presente numa proporção significativamente alta de pacientes (entre 10$67 \%$ daqueles com doença primária, devendo-se esta variação aos diferentes critérios de classificação utilizados nos estudos clínicos e na seleção de pacientes). Observam-se inadequada capacidade de acidificação renal e proteinúria leve. A biópsia renal revela infiltração intersticial linfocítica com destruição do interstício renal.

A maioria dos pacientes apresenta comprometimento na secreção de íons hidrogênio nos túbulos coletores (distais), caracterizando o quadro de acidose tubular renal hiperclorêmica distal (tipo 1), com hipocalemia. Verifica-se também hipostenúria, devido à interferência no mecanismo de concentração urinária. Menos comumente pode ser diagnosticado quadro de acidose tubular renal proximal (tipo 2) com síndrome de Fanconi, em que, devido a um defeito generalizado no transporte do 
túbulo proximal, os pacientes se apresentam com uma ampla variedade de anormalidades laboratoriais, incluindo a glicosúria com glicose sérica normal, a hipofosfatemia, a hipouricemia, a hipocalemia, a aminoacidúria generalizada e a proteinúria de baixo peso molecular.

Doenças auto-imunes, dentre elas a síndrome de Sjögren, constituem causas importantes de acidose tubular renal distal em adultos. Não é incomum a acidose tubular renal abrir o diagnóstico de síndrome de Sjögren, podendo ocorrer até mesmo anos antes de a doença estabelecer-se clinicamente ${ }^{(2)}$. Diante, portanto, de um quadro de acidose tubular renal distal, a possibilidade da presença de síndrome de Sjögren não deve ser desconsiderada.

Pacientes com acidose renal tubular distal apresentam doença de maior duração, maior freqüência de proteinúria e hipertensão, bem como níveis significativamente superiores de creatinina e $\$ 2$-microglobulina séricas, quando comparados a pacientes com capacidade normal de acidificação urinária ${ }^{(3)}$.

$\mathrm{Na}$ acidose tubular renal distal, o $\mathrm{pH}$ urinário mantém-se anormalmente elevado (acima de 5,5 ) na presença de acidose sistêmica. Ocorre retenção progressiva de íons hidrogênio com queda na concentração de bicarbonato para até menos de $10 \mathrm{mEq} / \mathrm{L}$. A perda de potássio relaciona-se com a diminuição na secreção distal de íons hidrogênio. A secreção de potássio aumenta visando à manutenção da neutralidade eletrolítica, enquanto o sódio está sendo reabsorvido (Tabela 1 ).

TABELA 1

ACIDOSE TUbULAR RENAL TIPO 1 - CRITÉRIOS DIAGNÓSTICOS ${ }^{(4)}$

Acidose metabólica de hiato aniônico normal

pH urinário mínimo $>5,5$

Hiato aniônico urinário positivo

A acidose crônica diminui a reabsorção tubular de cálcio causando hipercalciúria e hiperparatireoidismo secundário leve. O tamponamento ósseo pela carga ácida metabólica diária contribui para a hipercalciúria e para o dano ósseo. Nos adultos, pode ocorrer osteomalácia. A excreção de citrato é baixa, pois a acidose e a hipocalemia estimulam a reabsorção de citrato pelo túbulo proximal. Em conjunto, a hipercalciúria, a urina alcalina e os baixos níveis de citrato urinário aumentam em muito a propensão para formação de cálculos renais, nefrocalcinose e comprometimento da função renal. Em alguns casos, a depleção de potássio pode ser extremamente grave com potencial risco de vida se não prontamente diagnosticada e tratada (Tabelas 2 e 3 ).

TABELA 2

Alterações do CÁlcio e metabolismo ÓSSEO NA ACIDOSE TUBULAR RENAL TIPO 1

\section{hipercalciúria}

hiperparatireoidismo secundário

osteomalácia

TABELA 3

AlteraÇÕes RENAIS NA ACIDOSE TUbUlar RENAL TIPO 1

hipocitratúria com formação de cálculos renais

nefrocalcinose

diminuição da função renal

Há na literatura relatos freqüentes de paralisia hipocalêmica em pacientes com síndrome de Sjögren. Tsuboi et $a^{\left({ }^{5}\right)}$ descreveram que a paralisia periódica hipocalêmica foi observada em quase $40 \%$ dos pacientes com síndrome de Sjögren e acidose tubular renal distal. A paralisia hipocalêmica pode apresentar-se como a primeira manifestação da síndrome de Sjögren, precedendo os sintomas de xerostomia e xeroftalmia ${ }^{(6-10)}$. O diagnóstico de síndrome de Sjögren primária deve, portanto, ser considerado em mulheres pré-menopáusicas que se apresentam com fraqueza rapidamente progressiva e hipocalemia com ou sem síndrome sicca.

A função renal em pacientes com paralisia hipocalêmica tende a mostrar-se reduzida se comparada à de pacientes 
com síndrome de Sjögren primária e acidose tubular renal distal, mas sem história de paralisia hipocalêmica. A paralisia hipocalêmica, portanto, pode servir como marcador de doença renal mais grave em pacientes com síndrome de Sjögren primária e acidose tubular renal distal ${ }^{(2)}$.

Na literatura, são poucos os casos que relatam parada respiratória atribuída à hipocalemia decorrente de acidose tubular renal distal. Quando se restringe à síndrome de Sjögren como causa da hipocalemia são encontrados ainda menos casos descritos ${ }^{(11,12,7)}$.

O nível sérico de potássio não parece definir a ocorrência de parada respiratória. Não são observadas diferenças significativas nos níveis de potássio entre os pacientes que progridem para parada respiratória e aqueles que manifestam paralisia muscular somente. Possivelmente, a progressão para parada respiratória baseia-se mais em diferenças individuais de sensibilidade da musculatura respiratória à hipocalemia do que no nível sérico de potássio em si ${ }^{(12)}$.

Com suporte respiratório adequado e rápido reconhecimento do estado hipocalêmico como causa da falência respiratória, a suplementação parenteral de potássio permite rápida e completa recuperação. $\mathrm{O}$ tratamento da acidose tubular renal do tipo 1 (Tabela 4 ) baseia-se na administração de suplementos alcalinos na quantidade suficiente para titular a produção ácida metabólica diária, comumente ao redor de $0,5-2,0 \mathrm{mEq} / \mathrm{kg} /$ dia, divididos
TABELA 4

Tratamento DA ACIDOSE TUbUlar RENAL TIPO 1

suplementação alcalina: bicarbonato de sódio e solução de Shohl

sais alcalinos de potássio se hipocalemia persistente

aumento da dose de álcalis na vigência de doenças intercorrentes

de quatro a seis administrações. O bicarbonato de sódio (l a $3 \mathrm{mEq} / \mathrm{kg} /$ dia) e a solução de Shohl (l mmol de citrato de sódio e $1 \mathrm{mmol}$ de ácido cítrico por $\mathrm{mL}$, em uma dose variável de 60 a $100 \mathrm{~mL} /$ dia) são tratamentos habitualmente empregados. Sais alcalinos de potássio devem ser utilizados no caso de hipocalemia persistente. Indica-se aumento da dose de álcalis até normalização da acidose e hipercalciúria. Faz-se regularmente o monitoramento do tratamento através de medidas séricas de potássio, cloreto e perfil ácido-básico. Na vigência de doenças intercorrentes há necessidade de aumento na dose de álcalis (bicarbonato de sódio), geralmente não chegando a ultrapassar 4,0 mEq/kg/ $\mathrm{dia}^{(4)}$.

Declaramos a inexistência de conflitos de interesse.

\section{REFERÊNCIAS}

1. Hochberg MC, Silman AJ, Smolen JS, Weinblat ME, Weisman MH: Rheumatology - Third Edition, Mosby, 2003. Capítulo 130, página 1434.

2. Shenavandeh S: Sudden Paralysis and Metabolic Acidosis. Shiraz E-Medical Journal 3, 2002.

3. Pertovaara M, Korpela M, Kouri T, Pasternack A: The occurrence of renal involvement in primary Sjögren's syndrome: a study of 78 patients. Rheumatology 38: 1113-20, 1999.

4. Braunwald E, Fauci AS, Kasper DL, Hauser SL, Longo DL, Jameson JL: Harrison Medicina Interna, $15^{\underline{a}} \mathrm{ed}$, Rio de Janeiro, Editora McGraw-Hill Interamericana do Brasil Ltda, 2001. Capítulo 276, páginas 1695-6.
5. Tsuboi Y, Niijima K, Jyoshita Y et al: A case of renal tubular acidosis type I RTA with Sjögren's syndrome, hypokalemic periodic paralysis, and selective hypoaldosteronism. Saishin Igaku 45: 610-17, 1990 .

6. Galesic K, Morovic-Vercles J, Vergles D, Racic I, Horvatic I: Primary Sjögren's syndrome and hypokalaemic paralysis-case report. Rheumatizam 51: 19-22, 2004.

7. Fujimoto T, Shiiki H, Takahi Y, Dohi K: Primary Sjögren's syndrome presenting as hypokalaemic periodic paralysis and respiratory arrest. Clin Rheumatol 20: 365-8, 2001.

8. al-Jubouri MA, Jones S, Macmillan R, Harris C, Griffiths RD: Hypokalaemic paralysis revealing Sjögren syndrome in an eldery man. J Clin Pathol 52: 157-8, 1999. 
9. Siamopoulos KC, Elisaf M, Moutsoupoulos HM: Hypokalaemic paralysis as the presenting manifestation of primary Sjögren's syndorme. Nephrol Dial Transplant 9: 1176-8, 1994.

10. Raskin RJ, Tesan JT, Lawless OJ: Hypokalemic periodic paralysis in Sjögren's syndrome. Arch Intern Med 141: 1677-8, 1981.

11. Poux JM, Peyronnet P, Le Meur Y, Favereau JP, Charmes JP,
Leroux-Robert C: Hypokalemic quadriplegia and respiratory arrest revealing primary Sjögren's syndrome. Clin Nephrol 37: 189-91, 1992.

12. Ohtani H, Imai H, Kodama $T$ et al: Severe hypokalaemia and respiratory arrest due to renal tubular acidosis in a patient with Sjögren syndrome. Nephrol Dial Transplant 14: 2201-3, 1999. 